\title{
Research on Talent Training for Future Outsourcing in the Era of AI
}

\author{
Yanchun Yang*, Hongfeng Sun \\ School of Data and Computer Science, Shandong women's University, Jinan, China \\ *Corresponding author
}

\begin{abstract}
This paper studied the training mode of outsourcing talent, as well as the training concept and goal innovation or reorganization in the AI era, timely and effectively responded to the impact of AI. From the historical logic of higher education responding to the change of the social era, it was the logical starting point to promote the development of outsourcing industry by taking the change of talent training mode as the fulcrum and the innovation or reorganization of concept and goal as the starting point.
\end{abstract}

Keywords: Talent training, Outsourcing, AI, Interdisciplinary, Inter-academic

\section{INTRODUCTION}

The concept of Artificial Intelligence (AI) was first proposed at the Dartmouth Academic Conference in 1956 [1]. The introduction of Hinton's deep learning technology in 2006 opened a third wave of AI. The breakthrough of image recognition technology in the 2012 ImageNet competition, especially by the maturing big data technology in 2016 and the fusion of high-performance computing and AI, had made countries around the world see the great economic value of the development of AI. In 2016 and 2017, AlphaGo, the intelligent robot, had triumphed over the world's highest-ranking professional go players, making human society even more aware of the great possibility of AI. Countries all over the world agree that $\mathrm{AI}$ is a new focus of international competition, a new engine of economic development, and a new opportunity for social construction. With the application of computers, not all professionals are in the field of computers, but all professionals need to have basic computer literacy. Therefore, higher education is the most important training carrier for all social professionals, and the change of talent training mode in the era of AI should not only concern the cultivation of AI professionals, but also the cultivation of talents in all fields. Educational institutions at home and abroad had taken measures, such as the Turing Class of Peking University, the School of AI Technology of China University of Science and Technology, the Experimental Course of Artificial Intelligence Top-notch Talent Training of Xi'an Jiaotong University, and the Institute of Artificial Intelligence Plan of Nanjing University, etc. Manchester University of England had made full use of its interdisciplinary research advantages in the fields of medicine, health science, physics science, life science and humanities, and had encouraged students to take other AI courses in addition to compulsory computer science.

\section{TALENT TRAINING IN THE ERA OF AI}

Based on the logic of the reform on talent training mode, lots of researchers had studied the elements of the higher education talent training mode such as the concept and goal, the main body and the content of the training as the entry point, as well as the practical difficulties faced by the reform of the higher education talent training mode and the corresponding improvement path in the AI era. Duan Shifei and other researchers [2-3] had studied the reform of the higher education system in Britain in order to consolidate the traditional advantages in the field of AI and win global technological competition in the era of AI. Zhou Ruiwen [4] discussed the training of design education talents under AI. $\mathrm{Wu}$ Yuanyuan [5], starting with the advantages of AI, analyzed the current situation of accounting talent demand and training in the new period, and discussed the new mode of accounting talent training in the era of $\mathrm{AI}$ on this basis. Zhou Wenjuan [6] studied the way of educational change in the era of AI. Other scholars had studied the concept of higher education talents training, training goals, training models, evaluation methods and so on in the AI era [7-18], and some had discussed the role of teachers in the AI era [19-20]. For the training of service-oriented outsourcing talents, Lu Hongjuan [21] proposed the specific teaching stage suggestions in the study of outsourcing professional talent literacy training in the new era, but it aimed at the goal and requirement of outsourcing talent training in the Internet era. To sum up, although in the era of AI, higher education is facing changes, many scholars had carried out a lot of related research, but outsourcing talent training research in the era of $\mathrm{AI}$ is rarely found. 


\section{CURRENT SITUATION AND TREND OF OUTSOURCING INDUSTRY}

Since the implementation of the hundreds of thousands of projects in 2006, after more than ten years of rapid development, a promotion policy system and a development system of outsourcing model city as the main body were initially established, with which China had become the second largest outsourcing business recipient all over the world. Under the application of digital technology innovation and the driving of digital economy, outsourcing is becoming more and more high-end and diversified strategy, becoming the important carrier of global innovation resource optimal allocation and value chain decomposition and reconstruction, and is a new way for countries to participate in the global industrial division of labor and share the fruits of globalization.

On the new starting point of the profound adjustment of the international economic and trade map and the reform and opening up at home, the Party Central Committee and the State Council had integrated the top-level design of an open economy and proposed to promote the upgrading of service outsourcing. Facing the new situation, new tasks and new demands, it is necessary to earnestly change the thinking of development, to gather new momentum of development, to speed up the transformation and upgrading of the outsourcing industry, to play a leading role in the process of moving from an industrial-led economy to a service-led economy, and continuously inject new impetus into the construction of a strong country with an open economy. Outsourcing in China continued to grow relatively rapidly in the first half of 2018, with growth exceeding the same period last year. From January to June, a total of US \$82.297 billion in contract contracts were signed and 55.096 billion in contract execution completed, up to 17.06 percent and 9.58 percent respectively from the same period last year. The offshore outsourcing contract amounted to $\$ 5.1944$ billion and the offshore contract execution amounted to $\$ 33.849$ billion, up to $16.04 \%$ and $6.39 \%$ respectively from the same period last year. With the gradual improvement and maturity of China outsourcing industry chain, the whole industry was accelerating the pace of upgrading and transformation, and the continuous integration and innovation development to vertical industry and horizontal field.

Outsourcing enterprises from the initial simple manpower outsourcing to the solution provider transformation, deep into the industry, business rules and design standards, was familiar with the management process. Companies not only began to face high-end customers, but also began to subcontract to the global market, integrated allocation of international resources. And deep ploughing was carried out in big data, cloud computing, Internet of things, intelligent mobile, block chain and other technical fields, enabling digital transformation. Therefore, in the era of AI, a comprehensive change in the training mode of outsourcing talents should be found from the macroscopic and systematic angle. This is not only an inevitable choice to improve the quality of outsourcing in China, but also an appropriate strategy for China to connect and lead the future world in outsourcing human capital market.

The unique academic value and application value of the research on AI in 2017 were endless, as in the Davos Economic Forum's Global Risk report, the biggest risk of global trade in 2017 was unemployment, and the culprit for this result was rising automation. The impact of AI was oriented to the whole industry, and the outsourcing industry was no exception. As robots and algorithms take on more tasks, the market demand for labor will be reduced. In January 2018, India's Economic Times reported that in India IT industry had laid off as many as 56,000 people and that it had reduced campus recruitment by 50 to 70 percent. 2018 is the tuyere of $\mathrm{AI}$, for the outsourcing industry, opportunities and challenges coexist [22]. AI was expected to enhance service capabilities, such as Gaozhi Special Company was using AI technology to manage customer finance; Youchuang data Technology Co., Ltd. completed policy data capture, input, proofreading work with the help of process robots.

At the same time, AI will expand the service field, intelligent security, intelligent transportation, intelligent government and other fields contain new opportunities. But $\mathrm{AI}$ is also likely to reduce the demand for outsourced business, and customers may use AI systems instead of outsourced services/artificial services, especially some simple, high-frequency service content. For example, the domestic easy to use AI customer service instead of $90 \%$ of the artificial customer service, Ali launched Ali Xiaomi, NetEase self-built NetEase seven fish to complete customer service work, China Unicom and Baidu cooperated in the field of AI customer service, and so on.

\section{OUTSOURCING TALENT TRAINING MODE IN THE AI ERA}

Facing the new tuyere, China outsourcing industry had the potential of high-quality development, which was bound to move towards the stage of high-quality development. In 2018, the outsourcing industry shifted more from a customized one-to-one service to a platform-based one-to-many service [23], from a linear growth in human resource pricing to a project-shared nonlinear growth, from relying on manual to relying on technological advances, and from a single service activity to an integrated solution service in the industry.

Therefore, this paper studied outsourcing talent training mode in the AI era, including outsourcing talent training concept and goal innovation or reorganization, response to the impact of AI. The framework of outsourcing talent training mode in Shandong Women's University was shown as Fig. 1. 


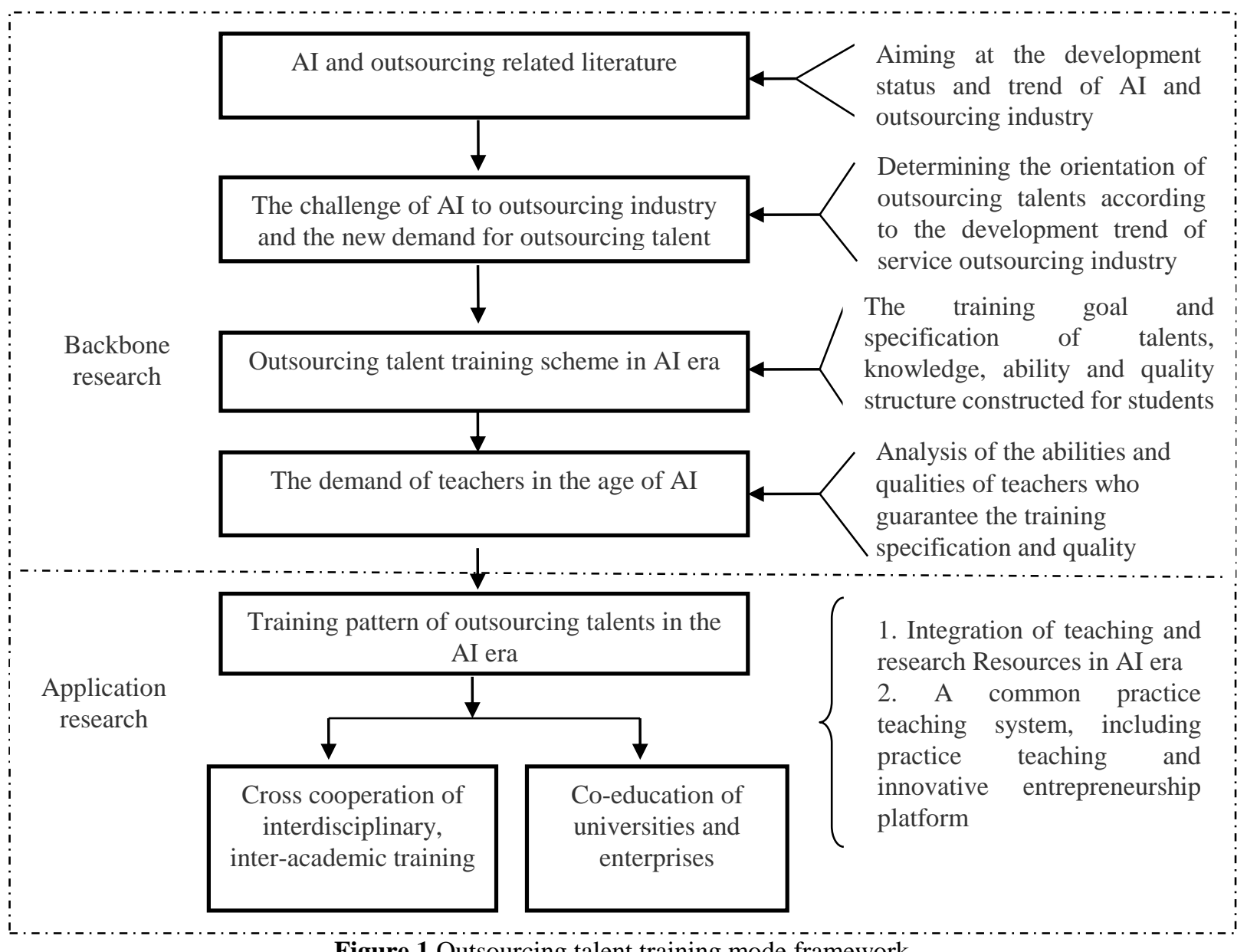

Figure 1 Outsourcing talent training mode framework

On the basis of studying the influence of AI on higher education, the demand of outsourcing business was analyzed with the help of the statistics of outsourcing industry in china, the knowledge, ability and quality of outsourcing talents in the future were discussed, and were applied to the current outsourcing training. The research ideas were shown in Fig. 2. 
Literature research method: combing literature and research ideas

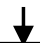

Statistical Analysis and Quantitative Analysis: The Challenges and New Demand of Service

Outsourcing Industry in the Age of AI

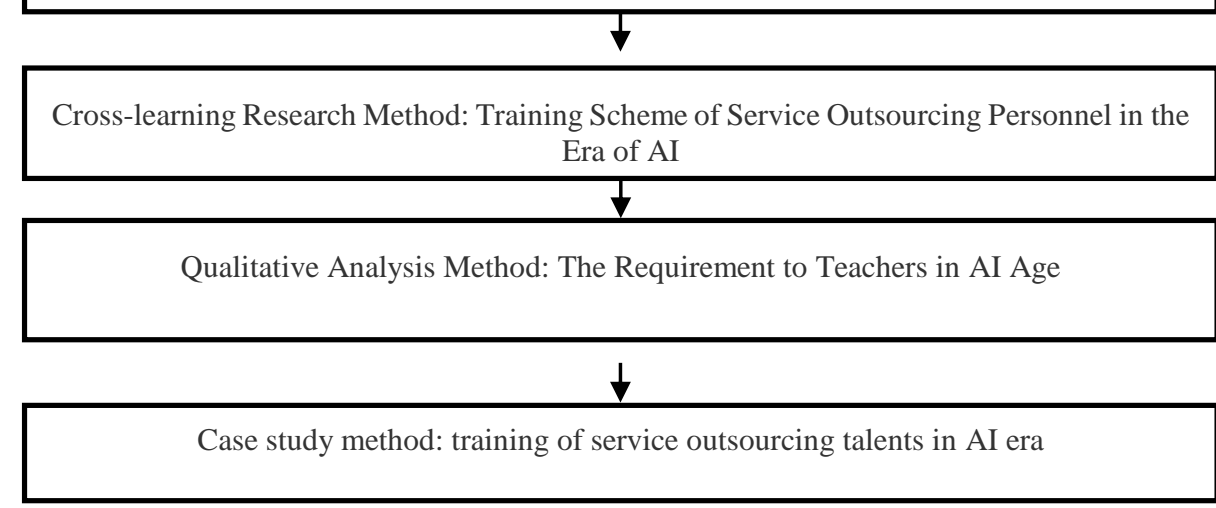

Figure 2 Research ideas

\section{SUMMARY}

This paper focused on the new demand for outsourcing personnel in the era of AI, analyzed the implementation path of outsourcing talent training mode, and thus determined four key problems: training orientation, training scheme, teacher team construction scheme, training mechanism, and taking outsourcing talent training in Shandong Women's University as an example to study the new mechanism of co-education between schools and enterprises.

\section{ACKNOWLEDGEMENT}

This research was financially supported by the Cooperative Education Project of Higher Education Department of Ministry of Education of China (Grants No. 201702020004).

\section{REFERENCES}

[1] Big data. The History of Artificial Intelligence [EB/OL]. [2017- 08- 24]. http:/ /www.36dsj.com/ archives/ 23411.

[2] Zhao Zhixing, Duan Xinxing. Reform of Higher Education Talent Training Model in the Age of Artificial Intelligence: Basis, Dilemma and Path [J]. Journal of Southwest University for nationalities,2019(2).
[3] Duan Shifei, Zhang Wei. A Study on the Change Trends of Higher Education in Britain in the Age of Artificial Intelligence $[\mathrm{J}]$. Comparative Education Research,2019(1).

[4] Zhou Ruiwen. New Age and New Challenge Cultivation of Design Education Talents under Artificial Intelligence $\quad[\mathrm{J}]$. Vocational Education Perspective,2018(12).

[5] Wu Yuanyuan. A probe into the New Mode of Accounting Talent Training in the Age of Artificial Intelligence [J]. Time Finance,2018(12).

[6] Zhou Wenjuan. A Study on the Reform of Education in the Age of Artificial Intelligence [J]. Journal of Zhengzhou Institute of Light Industry (Social Sciences),2018(12).

[7] Nie Jianfeng. Analysis on Several Key Issues of Talent Training Model in Universities [J]. Journal of the National Institute of Education Administration,2018(3).

[8] https://www. Weforum.org /reports /the future of jobs

[9] https: / /www.citivelocity.com/citigps/technology work v2-0 /.

[10] https://www.gartner.com/en /human-resources /talentneuron /future-proof -your-talent- strategy.

[11] Xu Guoqing. Fundamental Transformation of Talent Training Model in Vocational Education in Intelligent 
Age [J]. Educational Research,2016(3).]. High-Tech Newsletter,2017(8).

[12] Jia Jiyou. Artificial intelligence enabling education and learning [J]. Journal of Distance Education, 2018(1).

[13] Yu Hongliang. Knowledge Reform and Curriculum Renewal in the Digital Age [J]. Teaching materials. Teaching Law, 2017(2).

[14] Li Deyi, Ma Nan. New Engineering in Intelligent Age -- Practice of Artificial Intelligence Promoting Education Reform [J]. Higher Engineering Education Research,2017(5).

[15] Li Liguo. Higher Education Talent Training Model in Industrial 4.0[ J]. Educational Research at Tsinghua University,2016(1).

[16] Current Situation of Artificial Intelligence Education in Colleges and Universities in China: It'should be established first - level discipline. [EB /OL]. (2018-04-20) [2018-11-05]. https: / /baijiahao. baidu. $\mathrm{com} / \mathrm{s}$ ? id $=1598265277020701773 \& \mathrm{wfr}=$ spider \&for $=$ pc.

[17] Zhang Daliang. To improve the ability of talent training, we should make great efforts on curriculum, teaching materials and teacher building $[\mathrm{J}]$. Chinese University Teaching, 2018 ( 5).

[18] Zhang Jianxiang. The connotation and essential characteristics of talent training performance evaluation in universities [J]. Educational research, 2018(3).

[19] Yu Shengquan. The Future Role of Artificial Intelligence Teachers [J]. Research on Open Education, 2018(1).

[20] Zhu Yongxin. Welcome the new era of human-computer co-education $[\mathrm{J}]$. China Education Journal, 2018(2).

[21] Lu Hongjuan. A Study on the Cultivation of Professional Literacy in Service Outsourcing in the New Era [J]. Scientific public, 2019(1).

[22] Red bayberry. China's service outsourcing transformation development path is clearer. International Business News. 2018.

[23] Li Xilin. China's service outsourcing industry transformation and upgrading direction, path and measures [J]. International trade. 2017(9). 